\title{
Disaster Risk Reduction: High Time We Address the Education and Practice Gap
}

https://doi.org/10.37719/jhcs.2020.v2i2.Ite001

\author{
NORIEL P. CALAGUAS, MSHSA, RN \\ https://orcid.org/0000-0003-0624-4287
}

Department of Nursing, School of Nursing and Allied Medical Sciences

Holy Angel University, Angeles City, Pampanga, Philippines

Corresponding author's email: ncalaguas@hau.edu.ph

Dear Editor:

In light of typhoons Rolly (Goni), Siony (Atsani), and Ulysses (Vamco) that have caused disastrous flooding and subsequent losses to both human life and property, the importance and implications of the study Disaster Risk Reduction Knowledge among local people in a Selected Community in the Philippines (Soriano, 2019), cannot be discounted. A disaster as defined by the United Nations International Strategy for Disaster Reduction (2016) is "a serious disruption of the functioning of a community or a society involving widespread human, material, economic or environmental losses and impacts, which exceeds the ability of the affected community or society to cope using its resources" (Najafi et al., 2017). Soriano (2019) described the sampled community members from Taytay, Rizal to possess a fair knowledge of disaster-related knowledge and disaster risk perception, good knowledge of disaster preparedness and readiness, disaster adaptation, and disaster awareness. Soriano also determined possible relationships between respondents' age, sex, civil status and educational attainment, and the community's level of disaster risk reduction (DRR) knowledge. None of the tested sociodemographic variables were seen to be correlated to the community's overall good level of DRR knowledge. I appreciate the study's contribution to local knowledge on DRR. I want to take this opportunity to motivate our readership to help bridge the DRR knowledge and practice gap through research.

Various Philippine agencies, local government units, and organizations may benefit from future studies that opt to include other variables like level of income, house ownership status, collective efficacy, locus of control, fatalism, anxiety, previous disaster experience, community participation and empowerment, responsibility towards others, and available resources in their analyses of DRR education (van Valkengoed \& Steg, 2019). If any of them are seen to have a relationship, causal or otherwise, with DRR knowledge, these variables can offer various institutions 
and organizations valuable insight into improving communities' collective knowledge.

In evaluating the effects DRR knowledge may have on DDR practices or behaviors, future researchers may look into framing their questions within various behavioral theories or models (Najafi et al., 2017). Research on DRR practice and behavior may utilize the social ecologic model, social cognitive theory, the transtheoretical model of change, the health belief model, the theory of reason action, and the technology acceptance model, which may provide a new perspective on Filipinos' DRR practices or behaviors. Testing the applicability and significance of these theories or models in the local context may better inform policy. Insights derived from theoretical inquiries may scaffold more efficacious behavior change interventions built on the existing DRR education programs.

The Philippines' many cultures, unique geography, and geologic features provide diversity in natural disasters' experiences based on which island, region, city, or municipality one is currently in. It could then be implied that a community's DRR knowledge and behaviors and their collective perception of the disaster-related risks may be vary based on their locale's predisposition to natural disasters. For this reason, I find the choice of Taytay, Rizal as research local to be interesting. The municipality of Taytay is often spared and is projected to be relatively safe from disastrous levels of flooding (DOST-UP DREAM \& Phil-LiDAR Program, 2017) owing to its relatively higher elevation when compared to neighboring municipalities in the province of Rizal that have been hit the hardest by flooding due to rainfall from the series of typhoons. I recommend that replication and extensions of Soriano's study be done in areas that are historically more prone to natural disasters. Replication of this research across other disaster-prone locales in the Philippines may provide a basis for a comparative analysis of DDR education programs' efficacy.

In closing, the work of Soriano (2019) should stimulate researchers to look into the reasons why many Filipinos failed to act accordingly based on DRR knowledge despite an acceptable or good level of DRR knowledge. We should continue researching ways to bridge the DRR education and practice gap. We can, through evidence-based and evidence-inspired research, help build more disaster-resilient communities in the Philippines.

\section{Conflict of Interest}

The author has no conflict of interest to disclose.

\section{Funding}

There is no funding to be declared. 


\section{References}

DOST-UP DREAM \& Phil-LiDAR Program. (2017). Taytay, Rizal 25 Year Flood Hazard Map. https://lipadfmc.dream.upd.edu.ph/layers/geonode\%3Aph045813000_fh25yr_10m

Najafi, M., Ardalan, A., Akbarisari, A., Noorbala, A. A., \& Elmi, H. (2017). The theory of planned behavior and disaster preparedness. PLoS currents, 9. https://doi.org/10.1371/currents.dis.4da18e0f1479bf6c0a9 $4 \mathrm{~b} 29 \mathrm{e} 0 \mathrm{dbf} 4 \mathrm{a} 72$

Soriano, G. (2019). Disaster Risk Reduction Knowledge among local people in a Selected Community in the Philippines. Journal of Health and Caring Sciences, 1(2), 92-99. https://doi.org/10.37719/jhcs.2019.v1i2.oa007

van Valkengoed, A. M., \& Steg, L. (2019). Meta-analyses of factors motivating climate change adaptation behavior. Nature Climate Change, 9(2), 158-163. https://doi.org/10.1038/s41558-018-0371-y

\section{About the Author}

Noriel P. Calaguas, MSHSA, RN, is a full-time Assistant Professor and the current Chairperson of the Department of Nursing at Holy Angel University. He earned his Bachelor of Science in Nursing (2011) and Master of Science in Health Services Administration (2019) at the same university. Before joining the academe, he worked as an HIV counselor in both government and non-government organizations. He has developed programs aimed at increasing awareness and prevention of HIV and other sexually transmitted diseases. He currently serves as a member of the Philippine Society of SRH Nurses board and a reviewer for international journals 